\title{
The Influence of Cisplatin on the Gas-Phase Dissociation of Oligonucleotides Studied by Electrospray Ionization Tandem Mass Spectrometry
}

\author{
Adrien Nyakas, Michael Eymann, and Stefan Schürch \\ Department of Chemistry and Biochemistry, University of Bern, Bern, Switzerland
}

cis-Diamminedichloroplatinum(II) (cisplatin, DDP) is a cornerstone of anticancer therapy and has become one of the most widely used drugs for the treatment of various epithelial malignancies. The cytotoxicity of cisplatin is mainly based upon its affinity to adjacent guanines in nucleic acids, resulting in the formation of 1,2-intrastrand adducts. In this study the gas-phase dissociation of DNA- and RNA-cisplatin adducts is investigated by electrospray ionization (ESI) tandem mass spectrometry (MS/MS). The fundamental mechanistic aspects of fragmentation are elucidated to provide the basis for the tandem mass spectrometric determination of binding motifs and binding sites of this important anticancer drug. It is shown that the binding of cisplatin to vicinal guanines drastically alters the gas-phase fragmentation behavior of oligonucleotides. The $3^{\prime}-\mathrm{C}-\mathrm{O}$ bond adjacent to the GG base pair is preferentially cleaved, leading to extensive formation of the corresponding $\mathrm{w}$-ion. This observation was even made for oligoribonucleotides, which usually tend to form c- and y-ions under CID conditions. The absence of complementary ions of equal abundance indicates that oligonucleotide-cisplatin adducts are following more than one dissociation pathway in the gas-phase. Several mechanisms that explain the increased cleavage of the $3^{\prime}-\mathrm{C}-\mathrm{O}$ bond and the lack of the complementary a-ion are proposed. Results of additional MS/MS experiments on methylphosphonate-oligodeoxynucleotides confirm the proposed mechanisms. (J Am Soc Mass Spectrom 2009, 20, 792-804) (C) 2009 Published by Elsevier Inc. on behalf of American Society for Mass Spectrometry

$\Omega$ is-Diamminedichloroplatinum(II) (cisplatin, DDP) revolutionized anticancer therapy like no other chemotherapeutic agent. The incidental discovery of its cytotoxic properties by Rosenberg et al. in 1965 and Hill's subsequent clinical tests in the $19 \mathrm{~s}$ were a breakthrough in oncology [1, 2]. It marked the start of an effective cancer treatment by enhancing the chances of a successful cure of various epithelial malignancies such as lung, head, neck, ovarian, bladder, and testicular cancer [3]. However, due to severe side effects, evolving resistance of cancer cells to cisplatin during treatment, and the problem that cisplatin cannot combat all types of cancer successfully, the development of potent platinum based alternatives such as carboplatin and oxaliplatin has become an important issue in cancer research $[2,4-6]$. From the very beginning, it was crucial to gain deeper insight into the pathway cisplatin follows in vivo and to determine its principal cellular targets as well as the mode of interaction. So far, experiments revealed that DDP reacts preferentially with DNA, but that other substrates, such as RNA, phospholipids and phosphatidylserine in membranes, as well as proteins and peptides, can serve as targets as

Address reprint requests to Dr. Stefan Schürch, Department of Chemistry and Biochemistry, University of Bern, Freiestrasse 3, CH-3012 Bern, Switzerland. E-mail: stefan.schuerch@ioc.unibe.ch well, even though to a lesser extent [7-18]. The cellular uptake is believed to be controlled by passive diffusion through the cell membrane, which is feasible for a neutral molecule such as cisplatin $[17,19,20]$. The biologically active substrate is formed in vivo after entering the cell, as the relatively high chloride ion concentration in blood prevents cisplatin from prior hydrolysis. However, the chloride concentration in the cytoplasm is far lower and thus, the positively charged monoaqua-complex $\left[\mathrm{Pt}\left(\mathrm{NH}_{3}\right)_{2} \mathrm{Cl}\left(\mathrm{H}_{2} \mathrm{O}\right)\right]^{+}$is formed, an electrophile that is reactive against any nucleophile present in the cell [3].

The N7 position of guanine as the most electron rich region of all nucleobases represents the most favored binding site of cisplatin, being preferred over N7 of adenine and N3 of cytosine [21]. After the monofunctional adduct is established, hydrolysis of the second chloride ligand takes place and the final bidentate form is generated [22, 23]. Fichtinger-Schepman et al. found that 1,2-intrastrand cross-links of cis-[Pt $\left.\left(\mathrm{NH}_{3}\right)_{2}(\mathrm{GpG})\right]$ constitute $47 \%$ to $50 \%$ of all adducts, followed by cis- $\left[\mathrm{Pt}\left(\mathrm{NH}_{3}\right)_{2}(\mathrm{ApG})\right]$ accounting for another $23 \%$ to $28 \%$. Furthermore, 1,3-intrastrand cross-links of non-adjacent guanines as well as interstrand adducts were observed in $8 \%$ to $10 \%$ of all digestion products [21]. Additional studies, including in vivo experiments, confirmed these results [24-28].
(C) 2009 Published by Elsevier Inc. on behalf of American Society for Mass Spectrometry. 1044-0305/09/\$32.00

doi:10.1016/j.jasms.2008.12.018
Published online December 31, 2008 Received September 25, 2008

Revised December 18, 2008 Accepted December 18, 2008 
As a consequence, the DNA double helix is considerably distorted and a bend towards the major groove and a widening of the minor groove could be observed $[29,30]$. Such structural alteration most likely interferes with replication and transcription, thus inhibiting DNA synthesis [31-35]. Particularly, transcription seems to have greater impact on apoptosis than initially expected [36-39]. Most publications about cisplatin-oligonucleotide adducts are focusing on localization of the exact adduct position within the sequence. Generally, enzymatic digestion in combination with liquid chromatography and mass spectrometry has been used [40-43].

MS/MS emerged to an excellent tool for obtaining sequence information of modified nucleic acids, which are resistant to degradation by classical methods. The main advantages of MS/MS are its independence from specific structural prerequisites of the oligonucleotide and the high degree of information obtained by a single experiment consuming minute amounts of sample only. The technique provides detailed information about platinated oligonucleotides, especially regarding structural modifications and cross-linking patterns.

During the past decades, there has been great progress in the characterization of oligodeoxynucleotides by tandem mass spectrometry. As one of the earlier soft ionization techniques, fast atom bombardment was found to be a suitable method to transfer di-, tri-, and tetra-nucleotides into the gas phase and it has been the method of choice for the ionization of small nucleic acids for a long time. Early FAB experiments revealed the unique dissociation behavior of oligonucleotides [44-46] and it was found that the deprotonated phosphate group plays a major role in the dissociation of native oligonucleotides [47]. In the 1990s mass spectrometric studies using ESI and MALDI further extended our knowledge on the gas-phase dissociation of DNA and RNA oligomers. In 1998, Wang et al. [48] proposed a charge-remote mechanism for the formation of [a B]-ions. Evidence supporting such mechanism was subsequently provided by the groups of Hillenkamp and Gross, based on H/D exchange experiments [49] and tandem mass spectrometry of methylphosphonatemodified sequences [50]. The preferred generation of cand y-ions upon dissociation of RNA was reported by Cerny et al. [51] in the 1980s. Later, mechanistic data on the dissociation of negatively charged oligoribonucleotides was provided by Schürch et al. [52,53], followed by a demonstration of RNA decomposition in gas phase by Andersen et al. in 2006 [54], who examined the dissociation of positively charged MALDI-generated tetranucleotides utilizing $\mathrm{H} / \mathrm{D}$ exchange experiments.

On the other hand, there are only few publications on tandem mass spectrometry of oligonucleotidecisplatin adducts. Initial experiments were carried out using DDP in conjunction with nucleobases or mononucleosides as well as platinated bis(nucleobase) compounds [55, 56]. The utilization of electron impact ionization (EI) was quite problematic due to the high polarity and low vapor pressure of underivatized nucleosides, nucleotides, and oligonucleotides [57, 58]. However, Roos et al. used EI to investigate the interactions of cis- and trans-DDP with nucleoside analogues such as 1-methylcytosine and 9-methylguanine [56]. They mainly inferred the observed molecular and fragment ions from the corresponding isotopic ratio patterns, which led to some evidence for a preferred binding site. Furthermore, EI in conjunction with pyrolysis MS was applied to analyze a series of DNAcisplatin complexes by Macquet et al. [59]. They observed a considerable change in the abundance of the $\mathrm{C}$ - and G-derived fragment ions after binding of five cisplatin molecules to 1000 bases of salmon sperm DNA and consequently, stated that these nucleobases constitute the primary site of interaction. Nine years later, Claereboudt et al. performed MS/MS experiments of cisplatin and its higher molecular weight analogues by using FAB mass spectrometry as well as laser microprobe mass spectrometry (LAMMA) [60]. They obtained structurally significant fragment ions for e.g., $1 R, 2 R$-diaminecyclohexane(oxalato)platinum(II) and diamine(malonato)-platinum(II). In case of cisplatin they mainly observed sequential loss of the ammine and chloride ligands.

The first reports on platinated oligonucleotides in connection with FAB tandem mass spectrometry were published in 1991 by Martin et al. [61] and in 1992 by Costello et al. [62]. They found consistently that loss of $\mathrm{NH}_{3}$ groups from the ligand sphere of platinum is one of the dominant reaction pathways together with $\mathrm{N}$ glycosidic bond cleavage. Additionally, Costello et al. demonstrated that fragments containing platinum as well as one or both guanines represent a prominent set of product ions after CID, thus, giving evidence for the cleavage of the N-glycosidic bond(s). This observation is in good agreement with a theoretical study by Baik et al. [63] who have shown that platination as well as protonation of guanosine (dGuo) drastically reduces the gas-phase heterolytic bond dissociation energy (BDE) of the N9-C1' glycosidic bond. They calculated that the BDE of $\mathrm{dGuo}(\mathrm{Pt})^{+}$is almost $80 \mathrm{kcal} \mathrm{mol}^{-1}$ less than the BDE of native dGuo $\left(\Delta H=140.9 \mathrm{kcal} \mathrm{mol}^{-1}\right)$. Hence, likely cleavage of the N-glycosidic bond is selectively promoted when DDP is bound to a nucleobase. Furthermore, the authors suggested the formation of a 5-coordinate platinum as an intermediate species in the fragmentation process, which the phosphate oxygen is involved in. Moreover, Martin et al. showed, that platination generally results in stabilization of the oligonucleotide and a significant decrease of the abundance of fragment ions.

More recent MS/MS studies were performed in combination with ESI or MALDI to take advantage of their soft ionization character. Iannitti-Tito et al. [64] performed ESI-MS/MS experiments on the cisplatin adduct of CACGTG, confirming the main findings of Martin et al. and Costello et al. ( $\mathrm{NH}_{3}$-loss, $\mathrm{N}$-glycosidic bond cleavage). In the negative ion mode, though, no sequence-specific fragmentation could be observed. 
However, analysis in the positive ion mode led to more extensive structural information regarding platinumcontaining ions, since platinated fragments are rather positively than negatively charged. To obtain conclusive sequence information, additional MS/MS experiments of the major product ions generated by collisional activation in the ion source were performed.

A recent tandem mass spectrometric study by Zhang et al. aimed at the elucidation of three-dimensional structures of nucleic acids cross-linked by cisplatin [65]. In this case they subjected the platinated dinucleotide $\mathrm{d}(\mathrm{GG})$ to sustained off-resonance irradiation (SORI) in a FTMS instrument equipped with a nanoESI source. They found the positively charged $\left[\mathrm{Pt}\left(\mathrm{NH}_{3}\right) \mathrm{G}_{2}\right]$ ion, which results from cleavage of both $\mathrm{N}$-glycosidic bonds, to be the most abundant fragment along with $\mathrm{a}_{1}-\mathrm{B}_{1}$ - and $[\mathrm{G}+\mathrm{Pt}]$-ions. The initial findings of Costello et al. and Martin et al. were approved in further studies by several groups. However, to our knowledge no fragmentation mechanism of platinated oligonucleotides has been published yet.

In the present study, the gas-phase dissociation of platinated oligonucleotides and methylphosphonateoligodeoxynucleotides has been investigated by electrospray ionization tandem mass spectrometry in the negative ion mode to elucidate the influence of cisplatin on the fragmentation pathways of oligonucleotides. The most characteristic fragment ions are discussed and three dissociation mechanisms, based on the data obtained from methylphosphonate oligonucleotides, are presented.

\section{Experimental}

\section{Oligonucleotides, Chemicals, and Solvents}

HPLC purified single stranded (ss) oligodeoxynucleotides (CGGCTT, CCGGTT, CCTGGT, CGTGCT, CCGGCTGGTT) were purchased from Microsynth (Balgach, Switzerland), whereas methylphosphonate-modified oligodeoxynucleotides were ordered from Eurogentec S.A. (Seraing, Belgium). Oligoribonucleotides (CGGCUU, CCGGUU, CCUGGU) were obtained from TriLink Biotechnologies (San Diego, CA). All oligonucleotides were used without further purification. The oligonucleotide solutions were prepared with concentrations of $50 \mathrm{pmol} / \mu \mathrm{L}$ in water:acetonitrile:triethyl amine (49: 49:2 vol/vol/vol). Acetonitrile was purchased in HPLC quality from Romil Ltd., Cambridge, UK. Fluka HPLC quality water (Sigma-Aldrich Chemie GmbH, Buchs, Switzerland) was used for all solutions.

cis-Diamminedichloroplatinum (II) was purchased from Sigma-Aldrich Chemical Co. (St. Louis, MO). After the DDP-solution has been incubated with water for $24 \mathrm{~h}$ at $37^{\circ} \mathrm{C}$ to form the reactive diaqua species $\left[\mathrm{Pt}\left(\mathrm{NH}_{3}\right)_{2}\left(\mathrm{OH}_{2}\right)_{2}\right]^{+}$, it was mixed with the oligonucleotide in a molar ratio of $1.2: 1(120 \mathrm{pmol} / \mu \mathrm{L}: 100$ $\mathrm{pmol} / \mu \mathrm{L}$ ) and incubated for another $24 \mathrm{~h}$ at $37^{\circ} \mathrm{C}$. Before mass spectrometric analysis, the reaction mix- ture it was diluted with water to yield a final concentration of $70 \mathrm{pmol} / \mu \mathrm{L}$, approximately.

\section{Mass Spectrometry}

All experiments were performed on an Applied Biosystems/MDS SCIEX QSTAR Pulsar hybrid quadrupole time-of-flight mass spectrometer (SCIEX, Concord, Ontario, Canada), equipped with a nanoelectrospray ion source (Proxeon Biosystems, Odense, Denmark). Oligonucleotides were analyzed in the negative ion mode with a potential of $-850 \mathrm{~V}$ applied to the nanospray needle. Nitrogen was used as the curtain gas. Tandem mass spectrometric experiments were performed with the precursor ions selected within a window of $\pm 1.5 \mathrm{~m} / \mathrm{z}$ units. Collision-induced dissociation was performed with collision energies of -20 to $-30 \mathrm{eV}$ using nitrogen as the collision gas. Spectra were acquired over a $\mathrm{m} / \mathrm{z}$ range from 100 to 2000. Calibration of the instrument was performed with caesium iodide and taurocholic acid (Fluka, Buchs, Switzerland). The Applied Biosystems Analyst QS software package was used for data processing.

\section{Results and Discussion}

\section{Binding of Cisplatin to Oligodeoxyribonucleotides (DNA)}

The mass spectra of the platinated 6-mers CGGCTT, CCGGTT, and CCTGGT provided proof of successful adduct formation. Triply and quadruply charged ions were observed most frequently. In some cases the loss of one or two ammine ligands could be observed, which is consistent with previous findings. For an unambiguous identification of the platinated precursor the calculated isotopic distributions were compared with the experimental results.

Subsequent tandem mass spectrometric experiments confirmed the preference of cisplatin to form adducts with adjacent guanines, since platinated fragments were solely detected if they contain at least one guanine. Furthermore, loss of one or two $\mathrm{NH}_{3}$ ligands was observed, which is also in good agreement with former studies. Moreover, it is striking that after addition of cisplatin the formation of the w-ion, which is generated by cleavage of the $3^{\prime} \mathrm{C}-\mathrm{O}$ bond next to the GG base pair, is considerably enhanced.

As a representative example for all hexanucleotides, the spectra of platinated and unplatinated CCGGTT, are shown in Figure 1. Comparison of the two spectra demonstrates the increase of the $\mathrm{w}_{2}$-ion $(\mathrm{m} / \mathrm{z}$ 625.09) abundance compared to the $\mathrm{w}_{1}$-ions $(\mathrm{m} / \mathrm{z}$ 321.05). This observation was also made for the other hexanucleotides CGGCTT and CCTGGT, which showed a strong increase of the $\mathrm{w}_{3}$ - and $\mathrm{w}_{1}$-ion abundance, respectively. (In the following paragraphs, these $\mathrm{w}$-ions, which are formed by cleavage of the $3^{\prime}-\mathrm{C}-\mathrm{O}$ bond at the $3^{\prime}$-side of the GG base pair, are referred to as $\mathrm{w}_{\mathrm{x}}$-ions). This 


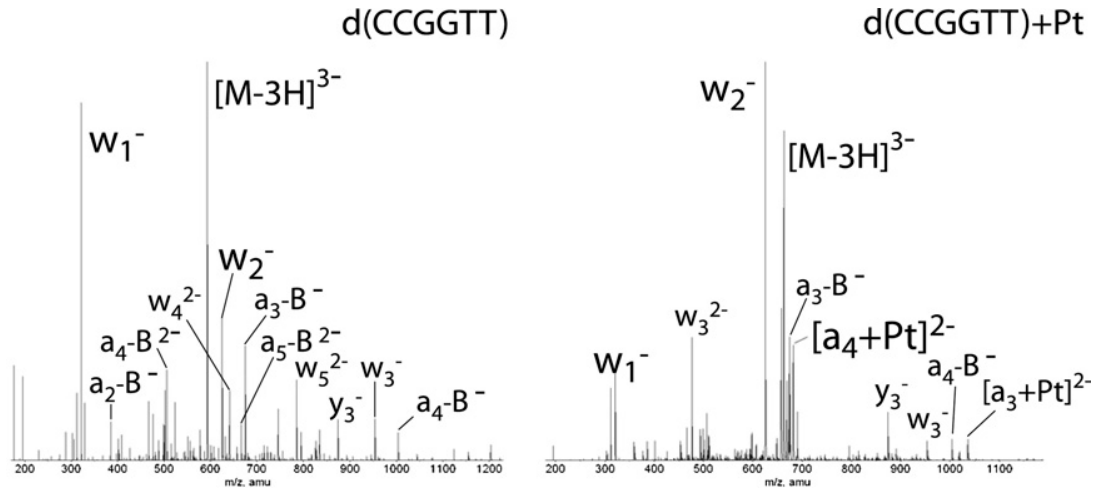

Figure 1. Product ion spectra of unplatinated and platinated CCGGTT. An increase of the $\mathrm{w}_{2}$-ion abundance is observed after addition of DDP.

particular aspect of the fragmentation depends on the presence of two adjacent or 1,3-vicinal non-terminal guanines within the nucleotide sequence and has not been described in literature yet. Our results clearly point out that the $3^{\prime}-\mathrm{C}-\mathrm{O}$ bond adjacent to vicinal guanines is particularly affected by the DDP moiety.

To validate the observation of a stringent $3^{\prime}-\mathrm{C}-\mathrm{O}$ bond cleavage after adjacent guanines, the decamer CCGGCTGGTT, which is able to bind two cisplatin moieties, was subjected to CID as well. The results are summarized in Figure 2 and Table 1. The abundant $\mathrm{w}$-ions reflect the preferred cleavage of the $3^{\prime}-\mathrm{C}-\mathrm{O}$ bond. Since the most abundant fragment ions are still those produced by backbone cleavage after the platination site $\left(w_{2},\left[w_{6}+D D P\right]\right)$, bond dissociation after platinated vicinal guanines also persists with longer sequences. For this reason the $3^{\prime}-\mathrm{C}-\mathrm{O}$ phosphate ester bond stability $3^{\prime}$ adjacent to both guanines seems to be generally influenced by the proximity of cisplatin, irrespective of the length of the oligonucleotide.

Among the platinated fragment ions, the $\left[\mathrm{a}_{4}+\right.$ Pt]-ion $(m / z$ 682.09) represents the most abundant dissociation product in the MS/MS spectrum of the CCGGTT-DDP adduct and constitutes the complementary ion to the $\mathrm{w}_{2}$ fragment (Figure 1). Generally, the $\left[\mathrm{a}_{n-\mathrm{x}}+\right.$ $\mathrm{Pt}$ ]-ion $(n=$ total number of nucleotides, and $\mathrm{x}=$ length of the $\mathrm{w}$ fragment ion resulting from cleavage on the 3 '-side of the GG base pair) represents the most abundant platinated fragment for all three hexamers. The fact that no complementary ions of comparable intensity are observed and that a- as well as a-B-ions are formed, suggests that most probably there are multiple fragmentation pathways, all leading to $\mathrm{w}_{\mathrm{x}}$-ions. The comparison of platinated and unplatinated fragment

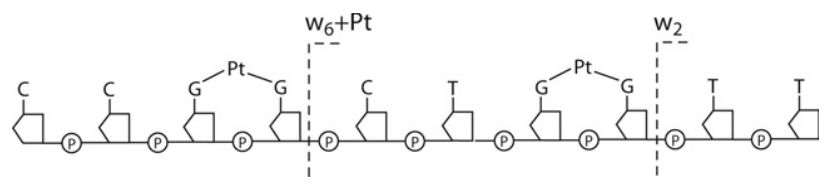

Figure 2. The $\mathrm{w}_{2^{-}}$and $\left[\mathrm{w}_{6}+\mathrm{Pt}\right]$-ions represent the preferred cleavage sites of the platinated decamer CCGGCTGGTT. ion intensities must be handled with care, taking into account the apparently reduced peak intensities of platinated ions caused by the broader isotopic distribution and peak splitting due to $\mathrm{NH}_{3}$-loss.

In general, the binding of cisplatin results in a considerable decrease of the diversity of the product ion spectra, which is clearly visible in Figure 1. It is unlikely that this effect is solely provoked by the presence of the platinum moiety, which holds two positive charges and hence, excludes short fragments from detection in the negative ion mode. Since the oligonucleotide sequences are long enough, most fragments should still be negatively charged and nevertheless, the a-B-series 5'adjacent to the cisplatin adduct could actually be generated just as normal for CCGGTT and CCTGGT.

The most abundant fragment ions observed upon CID of the hexadeoxynucleotide-cisplatin adducts are indicated in Figure 3. Backbone dissociation of all oligonucleotides was found to be influenced by DDP in a similar manner. Comparing the product ion spectra of the uncomplexed oligonucleotides with those of the platinated species, it is conspicuous that except for the site of platination, intensive fragmentation is quite restricted. Only the product ion spectrum of CGGCTT + DDP deviates from the spectra of the other oligonucleotides as it lacks the $\left[\mathrm{a}_{2}+\mathrm{Pt}\right]$ as well as the $\left[\mathrm{a}_{3}-\mathrm{G}+\mathrm{Pt}\right]$ fragment. However, these fragments would be neutral

Table 1. Relative intensities of $\mathrm{w}$-ions generated by CID of doubly platinated d(CCGGCTGGTT). The $\mathrm{w}$-ions resulting from cleavage of the 3-C-O bond next to the cisplatior adduct represent the most abundant fragments.

\begin{tabular}{ccc}
\hline Fragment & Unplatinated & $1 \times$ Platinated \\
\hline \hline $\mathrm{w}_{1}$ & 29.0 & 0.0 \\
$\mathrm{w}_{2}$ & 100 & 0.0 \\
$\mathrm{w}_{3}$ & 18.3 & 0.0 \\
$\mathrm{w}_{4}$ & 0.8 & 13.4 \\
$\mathrm{w}_{5}$ & 2.2 & 45.2 \\
$\mathrm{w}_{6}$ & 0.2 & 100 \\
$\mathrm{w}_{7}$ & 0.0 & 13.4 \\
$\mathrm{w}_{8}$ & 0.1 & 14.4 \\
$\mathrm{w}_{9}$ & 0.0 & 0.0 \\
\hline
\end{tabular}



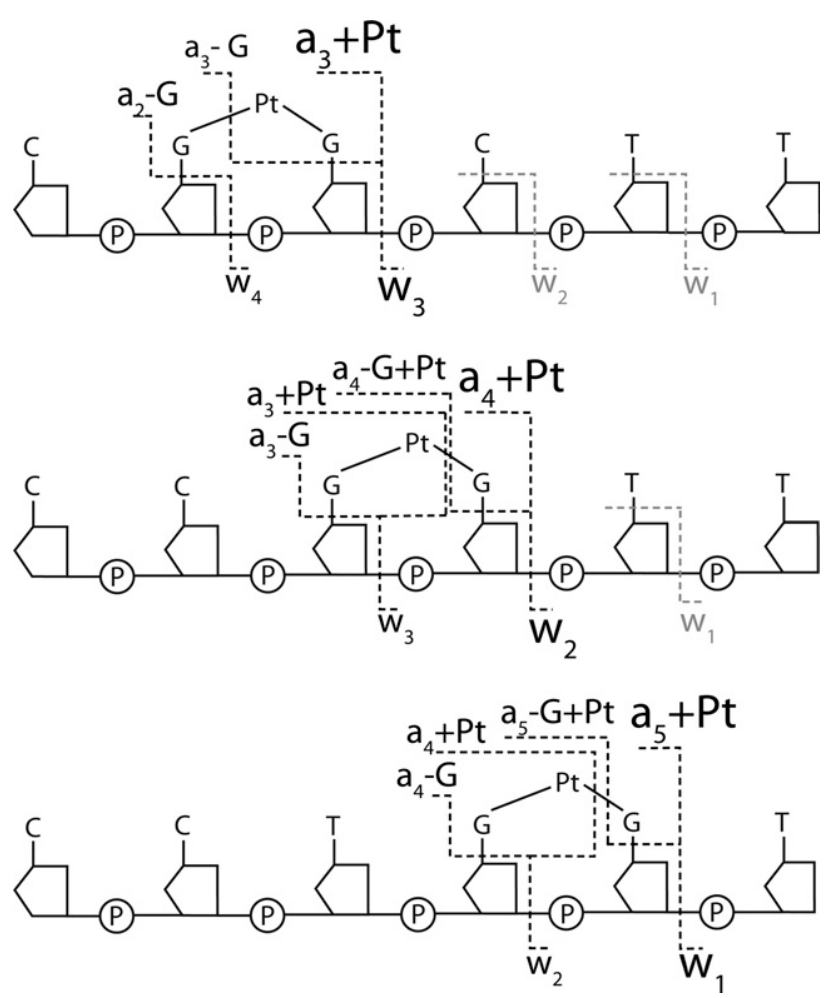

Figure 3. Most abundant fragments formed upon CID of platinated CGGCTT, CCGGTT, CCTGGT.

or even positively charged, which precludes their detection in the negative ion mode. Generally, short platinum-containing fragments might not be able to compensate for the positive charges introduced by the metal ion, thus, resulting in an uncharged or even positively charged fragment. Principally, backbone dissociation on the $5^{\prime}$-side of GG was found to be significantly reduced, whereas cleavage on the $3^{\prime}$-side of the vicinal guanines was affected less in comparison to the unplatinated species.

Our observations lead to the conclusion that cisplatin is promoting the generation of $\mathrm{w}_{\mathrm{x}}$-ions of platinated oligodeoxynucleotides in the gas phase and that fragmentation is basically limited to the vicinity of the GG-cisplatin adduct. In general, the extent of decrease in peak abundance of platinated fragment ions is affected by the choice of sequence, the charge state of the precursor ion, and the overall length of the oligonucleotide. When studying the dissociation of short model compounds in the negative ion mode, the limited number of phosphate groups might be insufficient to compensate for the two positive charges added by DDP. Consequently, the decrease in peak abundance is most likely influenced by the sequence length as well.

Cleavage of the N-glycosidic bond and loss of the nucleobase are key elements of the dissociation of oligodeoxynucleotides, as they induce subsequent backbone cleavage. Therefore, their role in the dissociation of platinated oligodeoxynucleotides had to be elucidated. The product ion spectra of platinated oligonucleotides show weak peaks corresponding to the negatively charged $\left[\mathrm{G}+\mathrm{Pt}\left(\mathrm{NH}_{3}\right)\right]$ - and [GG + Pt]-ions at $\mathrm{m} / \mathrm{z} 360.02$ and $\mathrm{m} / \mathrm{z} 493.03$, respectively, thus, giving evidence for cleavage of the N-glycosidic bonds. Furthermore, the observed masses of a-ions generated by dissociation of platinated oligonucleotides containing vicinal guanines suggests, that upon backbone dissociation next to the adduct site, at least one of the two $\mathrm{N}$-glycosidic bonds remains intact. As shown in Figure 4, the mass of a-ions with both N-glycosidic bonds remaining intact is one Dalton lower than the mass of an a-ion with one opened glycosidic bond. The product ion spectra of all hexanucleotides studied give evidence for [a $+\mathrm{Pt}$ ] fragments exhibiting an open glycosidic bond (data not shown).

Cisplatin is known to form 1,3-intrastand adducts as well. To obtain further evidence for the cleavage of the $\mathrm{N}$-glycosidic bond, the adduct of DDP with CGTGCT was subjected to CID. Besides the expected abundant peak of the $\mathrm{w}_{2}$-ion, the product ion spectrum shows two peak clusters at $\mathrm{m} / \mathrm{z} 792.61$ and $\mathrm{m} / \mathrm{z} 801.12$ (data not shown). They refer to the $\left[\mathrm{w}_{4}+\mathrm{Pt}+\mathrm{G}\right]$ and $\left[\mathrm{w}_{4}+\right.$ $\mathrm{PtNH}_{3}+\mathrm{G}$ ] fragment ions, and prove that both guanines are still bound to the $\mathrm{w}_{4}$ fragment. The presence of these fragment ions clearly shows that the $\mathrm{N}$-glycosidic bond of the second building block is cleaved. Disruption of the $3^{\prime}-\mathrm{C}-\mathrm{O}$ bond, which leads to formation of the $\left[\mathrm{w}_{4}+\mathrm{Pt}\right]$ fragment must be the consequence of prior cleavage of the corresponding $\mathrm{N}$-glycosidic bond. Additional evidence is provided by the doubly charged $\left[\mathrm{a}_{4}+\mathrm{Pt}\right]$ fragment with $\mathrm{m} / \mathrm{z}$ 689.59, since an intact $\mathrm{N}$-glycosidic bond would lead to a
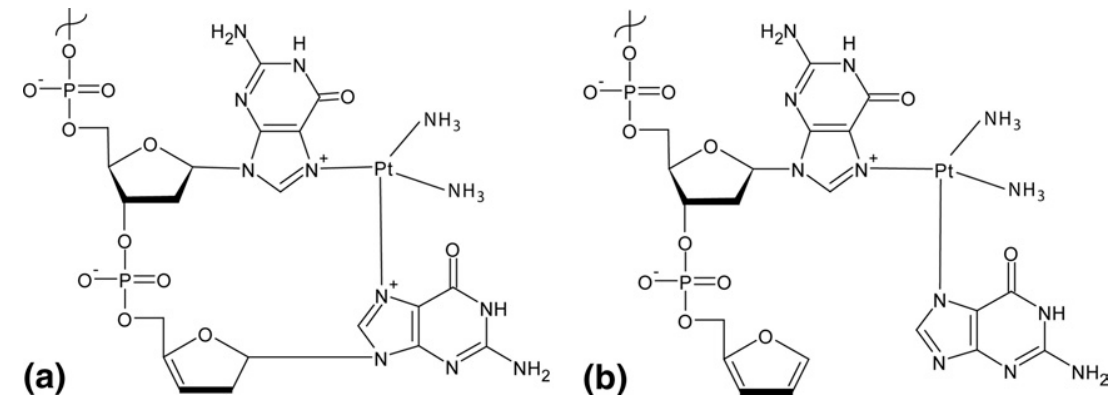

Figure 4. Structures of the [a $+\mathrm{Pt}]$-fragment with an intact and cleaved N-glycosidic bond, resulting in a mass difference of $1 \mathrm{Da}$. 
monoisotopic peak at $m / z$ 690.10. Cleavage of the $\mathrm{N}$ glycosidic bond is further promoted by formation of a stabilized furan ring due to additional abstraction of the $4^{\prime}-\mathrm{H}$ and cleavage of the $3^{\prime}-\mathrm{C}-\mathrm{O}$ bond.

Since a positive charge on the nucleobase weakens the N-glycosidic bond and accelerates its scission, the results of the MS/MS experiments met our expectations [66-69]. However, the presence of the $\left[a_{4}+\mathrm{Pt}\right]$ fragment clearly shows that the introduction of a positive charge on the nucleobase by platination does not automatically lead to cleavage of the N-glycosidic bond and therefore a thorough investigation of fragment ion formation is of major importance.

\section{Mechanistic Aspects of the Dissociation}

Based on the experimental data gained so far, the following conclusions can be drawn: (1) the binding of cisplatin influences the dissociation of oligonucleotides, (2) the $3^{\prime}-\mathrm{C}-\mathrm{O}$ ribose-phosphodiester bond is the pre- ferred cleavage site of platinated oligonucleotides, (3) at least one N-glycosidic bond at the adduct site is destabilized by the presence of cisplatin and consequently, cleaved preferentially, and (4) multiple dissociation pathways are responsible for the formation of the $\mathrm{w}_{\mathrm{x}}$-ion.

Elucidation of the dissociation mechanisms is based on comparison of the product ion spectra of unplatinated and platinated oligodeoxynucleotides, variation of the base sequences, and the study of methylphosphonate analogues. In Schemes 1 and 2 , two fragmentation mechanisms of platinated oligodeoxynucleotides are proposed, with CCGGTT as a representative sequence for all oligodeoxynucleotides studied. In both mechanisms the oxygen atom of the adjacent deprotonated phosphate group plays a key role, and both pathways result in formation of the $\mathrm{w}_{2}$-ion $\left(\mathrm{w}_{\mathrm{x}}\right.$-ion) due to backbone cleavage on the 3 '-side of the GG base pair, thus, explaining its generally high abundance in the product ion spectra. The initial steps of the mechanisms are in

\section{Mechanism 1}
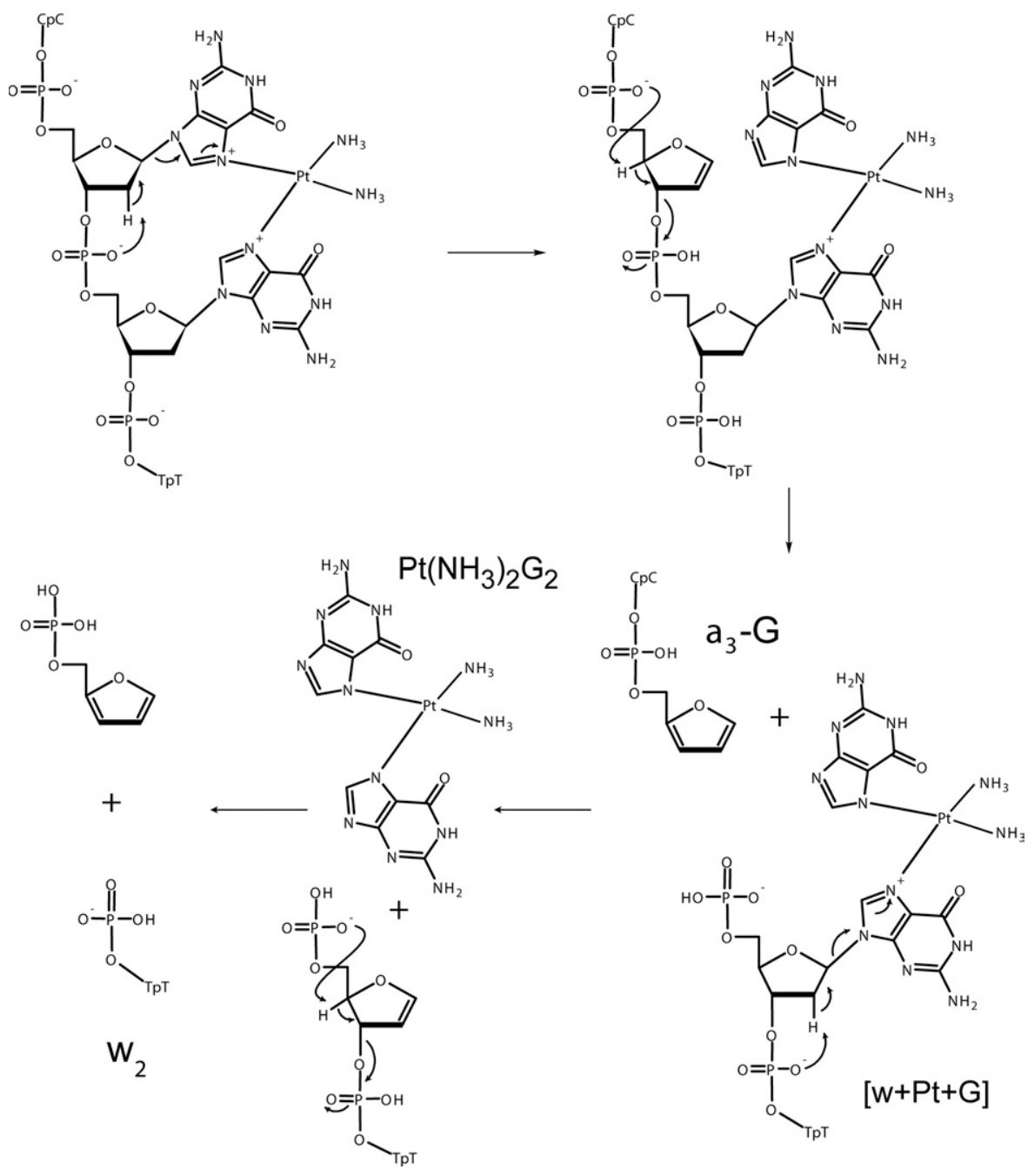

Scheme 1 


\section{Mechanism 2}
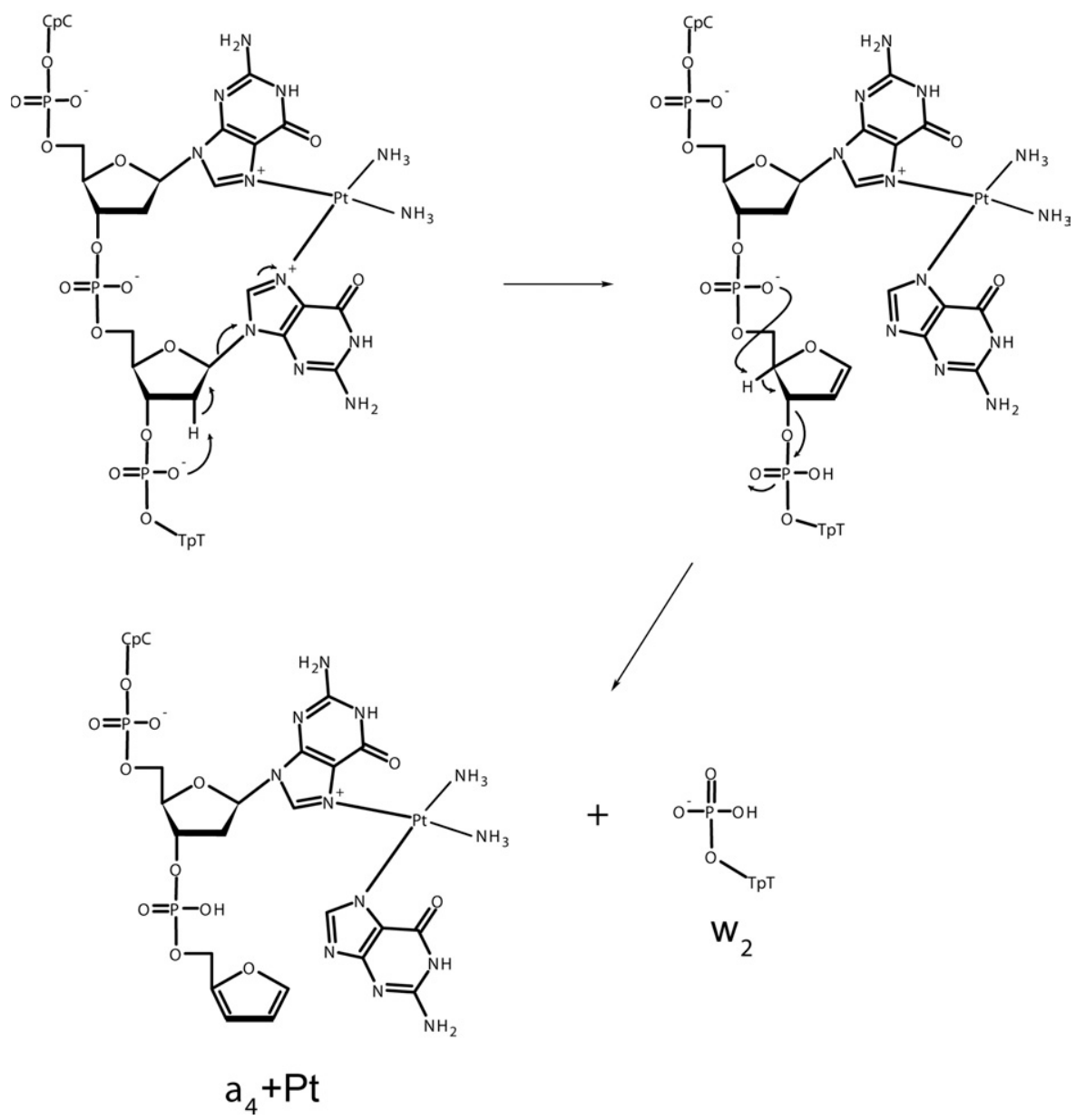

Scheme 2

analogy to one of the decomposition pathways proposed by Wan et al. for unmodified oligonucleotides [49]. However, in the present study the positive charge on the GG base pairs is a result of platination and not of protonation. The latter is believed to be a rather random event which can take place at any base of the oligonucleotide. On the contrary, the addition of cisplatin introduces two positive charges on a defined position within the sequence. Therefore, the proposed mechanisms are not valid for the formation of any fragment generated upon CID but they are highly specific for the formation of fragment ions resulting from cleavage in close vicinity of the cisplatin adduct.

Both mechanisms for platinated oligodeoxynucleotides are related, as both comprise a cascade of 1,2eliminations. They are initiated by attack of the 2 ' $-\mathrm{H}$ by an adjacent negatively charged phosphate oxygen, thus, resulting in cleavage of the corresponding N-glycosidic bond due to 1,2-elimination. Electron migration towards the platinum-N7 bond results in compensation of positive charge that has been introduced by DDP. In a second step, abstraction of the $4^{\prime}-\mathrm{H}$, preferably by attack from the adjacent $5^{\prime}$-phosphate oxygen, leads to a repeated 1,2-elimination and cleavage of the $3^{\prime}-\mathrm{C}-\mathrm{O}$ bond of the backbone.

In the first step of mechanism M1 (Scheme 1), abstraction of the $2^{\prime}-\mathrm{H}$ of the upper guanosine, carried out by the phosphate group between the two platinumbound guanosines, leads to scission of the N-glycosidic bond. In the second step, the 1,2-elimination reaction, which is triggered by the $5^{\prime}$-phosphate group leads to backbone cleavage and generation of the corresponding $[a-G]$ and $[w+P t+G]$ fragment ions with the nucleobase of the upper guanosine still bound to the released $\mathrm{w}$-ion via the $\operatorname{Pt}\left(\mathrm{NH}_{3}\right)_{2}$ moiety. In a further 1,2-elimination process the N-glycosidic bond of the second guanosine is cleaved, thus, releasing the $\mathrm{w}$-ion along with the $\mathrm{Pt}\left(\mathrm{NH}_{3}\right)_{2} \mathrm{G}_{2}$ moiety. Finally, cleavage of the $3^{\prime}-\mathrm{C}-\mathrm{O}$ bond results in the $5^{\prime}$-phosphorylated furan and a w-ion, which is one building block shorter than in the former intermediate.

In mechanism M2 (Scheme 2), the ribose $2^{\prime}$-position of the lower guanosine is initially attacked by the corresponding phosphate oxygen. Scission of the Nglycosidic bond and 1,2-elimination result in cleavage of the $3^{\prime}-\mathrm{C}-\mathrm{O}$ bond and release of the $[\mathrm{a}+\mathrm{Pt}]-$ and the 


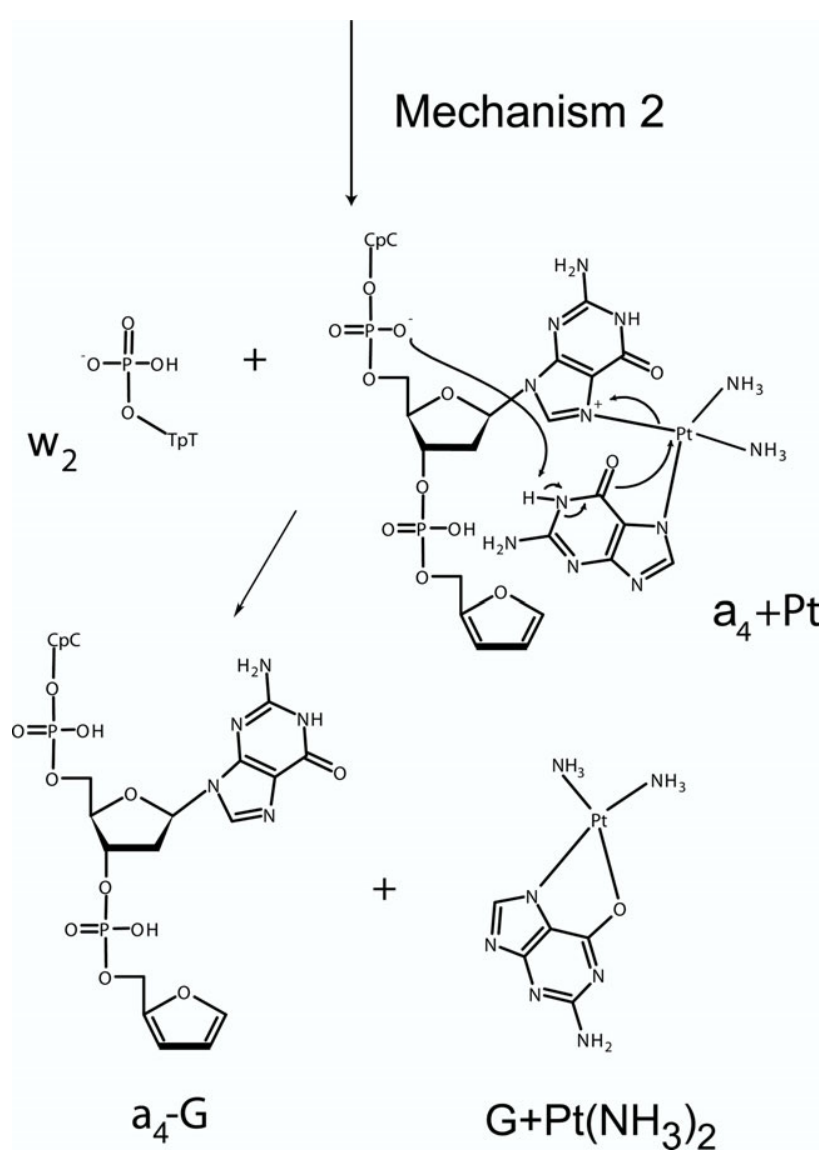

Scheme 3

$\mathrm{w}$-ion. Once the $[\mathrm{a}+\mathrm{Pt}]$-ion is formed, the dissociation can further proceed via the pathway shown in Scheme 3.

This pathway involves abstraction of the N1-proton of the released but still platinum-bound guanine by the phosphate group on the $5^{\prime}$-side of the upper guanosine. Subsequent electron rearrangement leads to formation of a platinum-guanine bidentate, while simultaneously breaking the bond between platinum and N7 of the upper guanosine. Along this pathway, the a-B and its complementary $\mathrm{w}$ fragment ion are generated. The plausibility of the formation of a platinum-guanine bidentate, as generated by the mechanism in Scheme 3, has been demonstrated by Carsey et al. [70], who, based on molecular orbital calculations, showed that DDP can bind equivalently to the N7 and O6 atoms of guanine, thus, suggesting the $\mathrm{O} 6$ atom to serve as a coordination center for platinum as well. Mechanisms M1 and M2 both lead to $\mathrm{w}$-ions, thus, explaining their enhanced abundance in the product in spectra of platinated oligonucleotides.

\section{Dissociation of Methylphosphonate-Modified Oligonucleotides}

To provide confirming information about the proposed dissociation mechanisms experiments on platinated methylphosphonate oligodeoxynucleotides have been performed, with CCGGTT as a representative nucleotide sequence. The sites of backbone modification are indicated in Figure 5. The introduction of methylphosphonatemodifications within the oligonucleotide backbone disables deprotonation at these positions, thus, masking potentially reactive sites. If a dissociation mechanism involves a certain phosphate group, substitution by a methylphosphonate will locally inhibit the corresponding reaction step, thus, blocking further degradation. The effect of selected modifications on the dissociation of the oligonucleotide will finally be observable as an alteration in the fragment ion pattern.

As demonstrated previously, the simultaneous appearance of a- and a-B-ions and the greatly enhanced abundance of the $\mathrm{w}_{\mathrm{x}}$-ion suggest, that multiple dissociation pathways apply to the dissociation of platinated oligodeoxynucleotides. The assumption of multiple pathways is further supported by the observation that the $\mathrm{w}_{\mathrm{x}}$-ion intensity remains quite unaffected by the introduction of single methylphosphonate-modifications at various positions within the backbone (spectra not shown). An almost complete exchange of the phosphate groups with methylphosphonates is required to inhibit the formation of the prominent $\mathrm{w}_{\mathrm{x}}$-ion. As shown in

MP-1

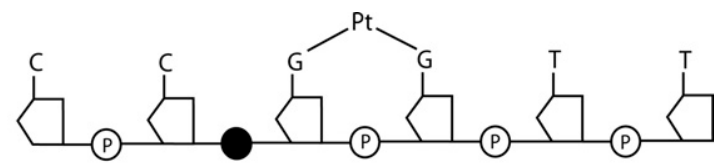

MP-2
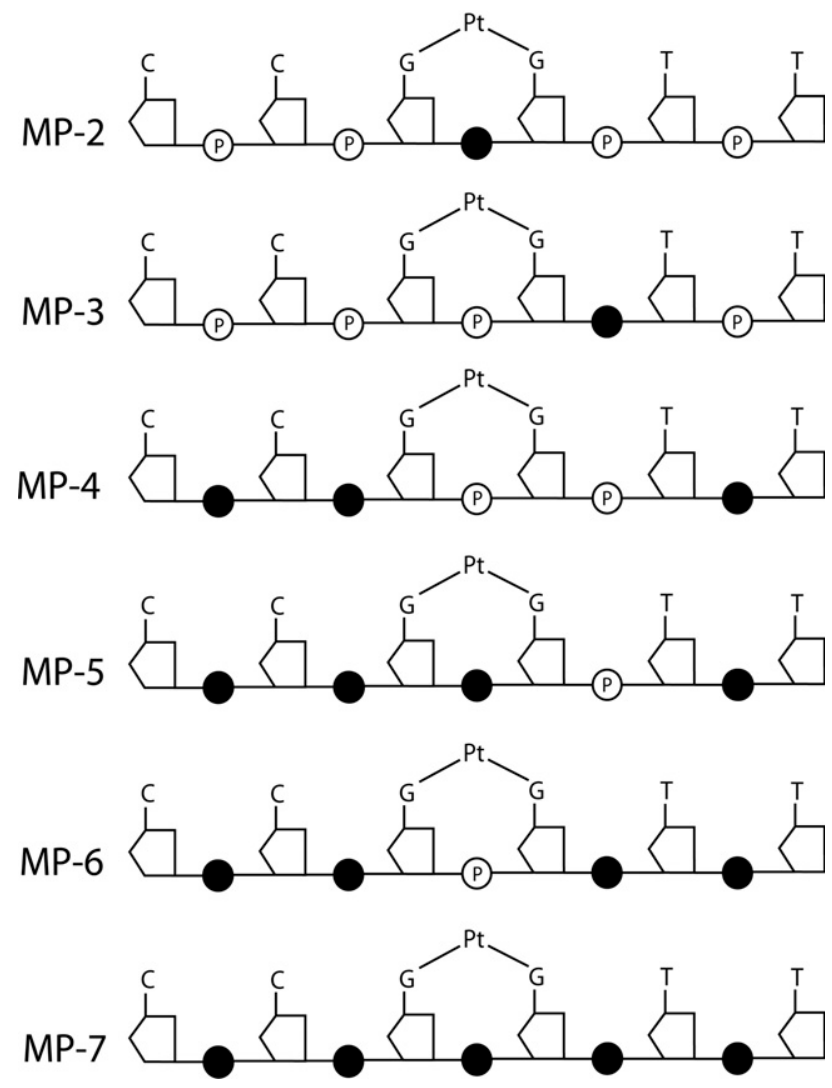

Figure 5. Methylphosphonate-modified hexamers. The black marker indicates the site of the modification. 


\section{CxCxGxGTxT+Pt}

(a)

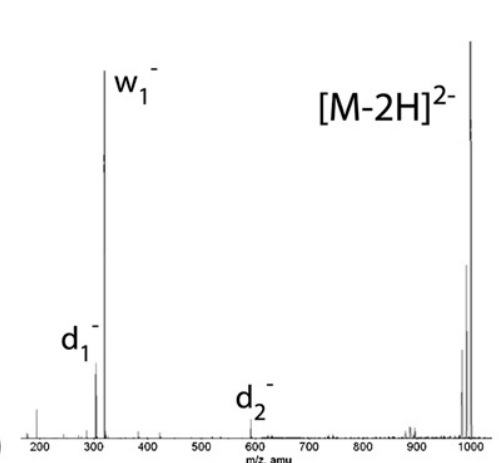

(b)

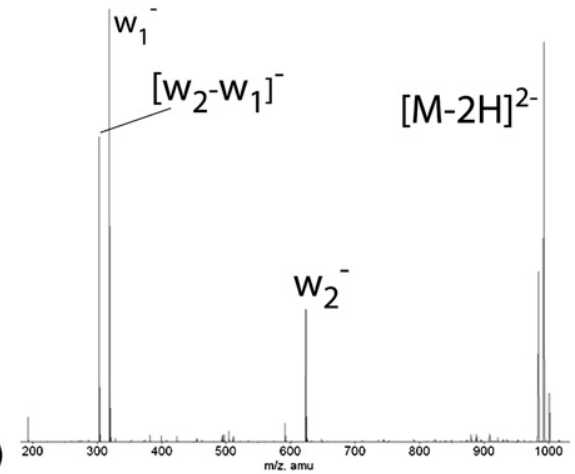

Figure 6. Product ion spectra of methylphosphonate-modified CCGGTT + Pt bearing one and two unmodified phosphate groups. As far as two phosphate groups in mechanistically relevant position remain unmodified, the $\mathrm{w}_{2}$-ion is observed in high abundance. Additionally, an overall decrease of the fragment ions is observed. (" $x$ " denotes the site of the modification).

Figure 6b, two unmodified phosphate groups in mechanistically relevant positions are sufficient to obtain $\mathrm{w}_{\mathrm{x}}$-ions of significant abundance. Also, secondary fragment ions, such as the $\left[\mathrm{w}_{2}-\mathrm{w}_{1}\right]$-ion in the product ion spectrum of CxCxGGTxT, are considered to derive from the $\mathrm{w}_{2}$-ion.

The fact that at least two unmodified phosphate groups are required to generate the $\mathrm{w}_{\mathrm{x}}$-ion, proves that both groups are involved in the mechanism thus, providing evidence for the proposed multi-step mechanisms. The strong peak of the $\mathrm{w}_{1}$-ion in Figure $6 \mathrm{a}$ can be ascribed to the attack of the $4^{\prime}-\mathrm{H}$ of the neighboring sugar ring by N1 of the terminal thymine. This mechanism is based on previous studies of methylphosphonatemodified oligonucleotides, which have been performed without the addition of cisplatin, though [71]. Since the attack does not occur in close proximity to the DDP adduct, such a mechanism is feasible.

Comparing the product ion spectra of unplatinated and platinated methylphosphonate-oligonucleotides it is generally striking that the number of fragment ion peaks is drastically decreased after addition of DDP, even more than in the case of unplatinated native oligonucleotides. Hence, fragmentation next to the GG base pair is even more favored for methylphosphonatemodified sequences. The intensity of the a-G- and [a + $\mathrm{Pt}$ ]-ions in the product ion spectra of methylphosphonateoligodeoxynucleotides changed significantly if the position of a single methylphosphonate-modification was shifted from the 5 '-side of the GG base pair to the $3^{\prime}$-side (MP-1 to MP-3 in Figure 5). Formation of the $\mathrm{a}_{4}-\mathrm{G}$ and $\left[\mathrm{a}_{4}+\mathrm{Pt}\right]$ fragment ion is almost completely inhibited for MP-3 and the abundance of the $\mathrm{a}_{3}-\mathrm{G}$-ion is significantly lowered in the product ion spectrum of MP-2, thus, reflecting the highly retarding effect exerted by the modification. However, the formation of both fragments is only weakly affected if phosphate groups at different positions are replaced by methylphosphonates, as revealed by CID of MP-4 to MP-7 (data not shown). These observations support the proposed mechanisms, as they point out the requirement of an unblocked 3'-phosphate group adjacent to a platinated guanosine for the initial cleavage step to take place.

In the product ion spectrum of MP-2, $\mathrm{a}_{4}-\mathrm{G}$ and $\left[\mathrm{a}_{4}+\right.$ $\mathrm{Pt}$ ] were observed with reduced abundance only. According to mechanism M2, the initial step, which involves attack of the 3 '-phosphate can take place. The reduced abundance of the fragment ions may be explained by the presence of the methylphosphonate in-between the two guanines, which blocks further degradation according to mechanisms M2. Similar observations were made for the reduced formation of $a_{3}-G$ from MP-1. The fact that these fragment ions are still observable despite formal blocking of the second reaction step gives evidence for different phosphate groups being able to carry out this dissociation pathway. Comparing these results with the proposed mechanisms there is an apparent coincidence regarding the first dissociation step. If the phosphate group carrying out the first attack is inactivated by a methyl group, the whole dissociation pathway is inhibited. However, masking of the phosphate oxygen atom, which acts in the second or third step of the reaction, has much less effect on the formation of the corresponding fragment. This observation suggests that once the fragmentation is initiated, a phosphate group in a remote position from the cleavage site is able to abstract the proton as well, though there is a clear preference for an attack from the adjacent phosphate group. This finding is consistent with the fact that the formation of the $\mathrm{w}_{2}$-ion is only inhibited if less than two phosphate oxygen atoms remain unmodified.

\section{Binding of Cisplatin to Oligoribonucleotides (RNA)}

GG specific cleavage was found for complexes of DDP with DNA. To investigate whether the tendency for 
a GG specific cleavage is unique for DNA oligonucleotides, the RNA analogues of all three hexamers (CGGCUU, CCGGUU, and CCUGGU) have been subjected to CID. Unlike DNA, which predominantly dissociates into a-B- and w-ions, RNA tends to form c- and $y$-ions upon CID. Therefore, an extraordinary abundance of $\mathrm{w}$-ions generated by dissociation of RNA adducts would be an unambiguous evidence for the influence of cisplatin on the dissociation of RNA.

In Figure 7 the spectra of unplatinated and platinated hexaribonucleotides are displayed. As expected in reference to previous studies, the spectra of all three unplatinated oligoribonucleotides (Figure 7a, c, and e) show the complete series of c- and y-ions. Additionally, $\mathrm{w}$-ions are generated with lower abundance. Two quite strong peaks of doubly charged ions with $\mathrm{m} / \mathrm{z} 565.40$ and $m / z 578.73$ refer to the loss of one guanine or cytosine, respectively. Overall, there are no peaks of extraordinary abundance, thus, indicating a balanced fragmentation behavior in absence of a favored cleavage site within the sequence. In contrast, the spectra of the corresponding cisplatin adducts all exhibit w-ion peaks of increased intensity. This fact is represented by the $\mathrm{w}_{3}$-ion peak $(\mathrm{m} / \mathrm{z} 466.55)$ in the product ion spectrum of CGGCUU + Pt (Figure 7b), the peaks of the singly and doubly charged $\mathbf{w}_{2}$-ions $(\mathrm{m} / \mathrm{z} 629.04$ and $\mathrm{m} / \mathrm{z}$ 314.04, respectively) from CCGGUU + Pt (Figure 7d), and finally, the all dominating $\mathrm{w}_{1}$-ion $(\mathrm{m} / \mathrm{z}$ 323.03) from CCUGGU + Pt (Figure 7f). These $\mathrm{w}$-ions are generated by cleavage of the $3^{\prime}-\mathrm{C}-\mathrm{O}$ bond adjacent to the vicinal guanines, and are referred to as " $\mathrm{w}_{\mathrm{x}}$-ions." $\mathrm{w}_{\mathrm{x}}$-Ions constitute the peaks of highest intensity in the product ion spectra of the hexaribonucleotide-cisplatin adducts. Considering the fact that $y$-ions are the predominant 3 '-terminal fragments of native RNA, the presence of highly abundant $\mathrm{w}_{\mathrm{x}}$-ions gives evidence for the altered dissociation due to adduct formation with cisplatin. Since the length of the $\mathrm{w}_{\mathrm{x}}$-ions varies with respect to a shift of the GG-DDP moiety, they can serve as an indicator for the position of the GG base pairs within the ribonucleotide sequences.

The preferred formation of $[\mathrm{a}+\mathrm{Pt}]$-ions, which was observed for DNA-cisplatin adducts, is much less pronounced in combination with RNA. Except for $\left[\mathrm{a}_{4}+\mathrm{Pt}\right]$ (a)

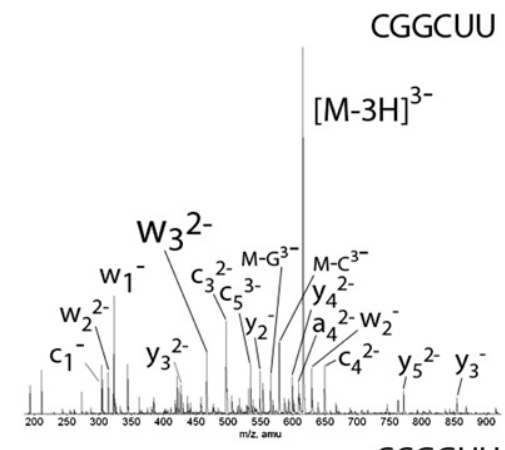

(c)

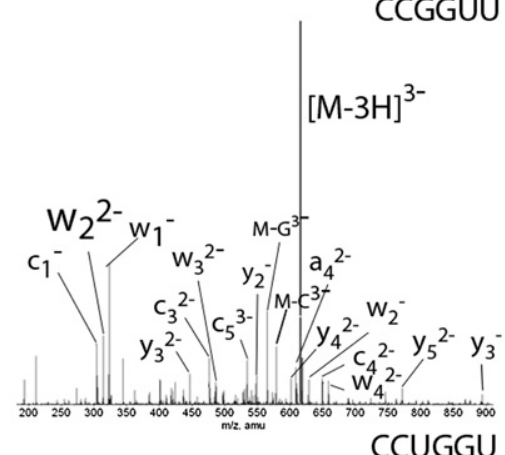

(e)

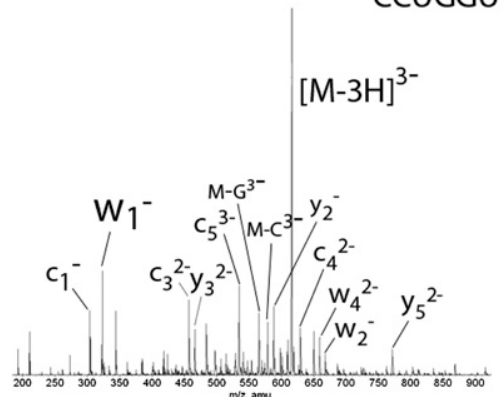

(b)

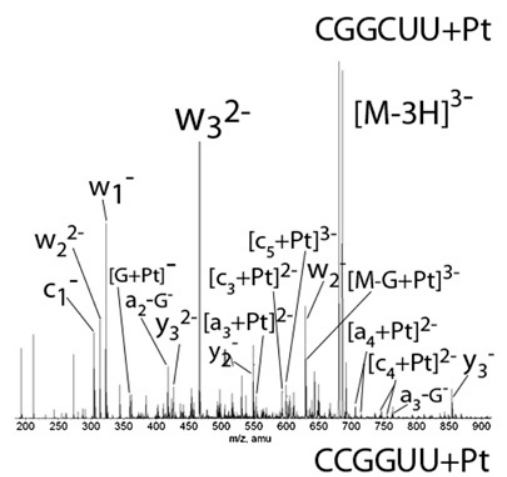

(d)

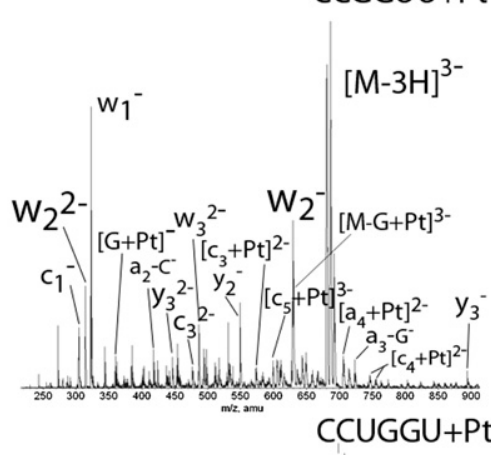

(f)

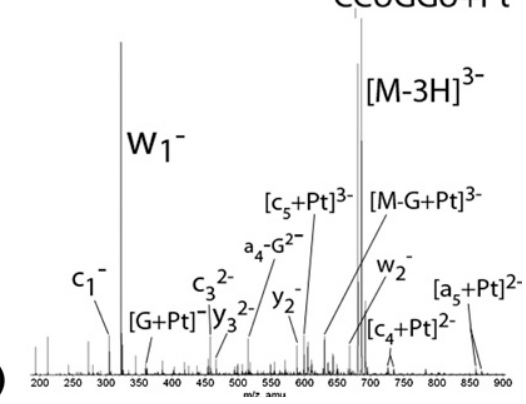

Figure 7. Product ion spectra of unplatinated and platinated RNA-hexamers. As for DNA an increase of the $\mathrm{w}_{\mathrm{x}}$-ion abundance is observed after the addition of DDP. 
from CGGCUU + Pt, all observable [a + Pt]-ions are generated by sequence-specific backbone cleavage after the GG base pair, namely $\left[\mathrm{a}_{3}+\mathrm{Pt}\right](\mathrm{m} / z$ 553.05) from CGGCUU + Pt, $\left[\mathrm{a}_{4}+\mathrm{Pt}\right](\mathrm{m} / z$ 705.56) from CCGGUU + $\mathrm{Pt}$, and $\left[\mathrm{a}_{5}+\mathrm{Pt}\right](\mathrm{m} / \mathrm{z}$ 859.10) from CCUGGU $+\mathrm{Pt}$, which all appear in rather low abundance. These $\left[\mathrm{a}_{n-\mathrm{x}}+\right.$ $\mathrm{Pt}$ ]-ions are complementary to the $\mathrm{w}_{\mathrm{x}}$-ions, thus, are indicative for the position of the GG base pair as well. Among the 5'-terminal fragments, the $[\mathrm{c}+\mathrm{Pt}]$-ions constitute the most prevalently formed cleavage products of platinated RNA (except for the $\left[\mathrm{a}_{n-\mathrm{x}}+\mathrm{Pt}\right]$-ion). The relative peak intensities as well as the total number of platinated ions are the largest for the c-series. Therefore, the conclusion can be drawn that platination does not alter the entire fragmentation of oligoribonucleotides but it does have a strong effect on the dissociation in close vicinity of the GG base pair.

Formation of the 3 '-terminal y-ions is only weakly affected by platination and there is no evidence for any platinated y-ion of considerable abundance. This finding is consistent with the results obtained from the investigation of oligodeoxynucleotides. $[y+\mathrm{Pt}]$-ions would derive from bond cleavage on the 5 '-side of the GG-cisplatin moiety, and experiments on DNA analogues already revealed a clearly reduced fragmentation on this side of the GG base pair as a result of cisplatin addition. Also, the tendency for reduced generation of cleavage products on the $5^{\prime}$-side of the vicinal guanines is as noticeable for RNA as it is for the DNA analogues studied previously. Due to the position of GG this effect is less pronounced for CGGCUU $+\mathrm{Pt}$ and CCGGUU $+\mathrm{Pt}$ than for CCUGGU $+\mathrm{Pt}$. For platinated CGGCUU and CCGGUU, the peak of the singly charged $c_{1}$-ion $(m / z 304.04)$ and the peak of $\left[a_{2}-\right.$ C] $(\mathrm{m} / \mathrm{z} 418.08$, exclusively in the spectrum of CCGGUU + $\mathrm{Pt}$ ) are the only representatives of fragment ions that derive from the $5^{\prime}$-side of GG. Even CCUGGU $+\mathrm{Pt}$, with the guanines shifted toward the $3^{\prime}$-end, shows strong suppression of fragment ion generation on the $5^{\prime}$-side of GG, with $c_{1}(m / z 304.0), c_{3}(m / z 457.05)$, and $y_{3}$ $(m / z 466.06)$ as the only observable fragments from this part of the sequence. No further fragments belonging to the $y$ - or w-ion series in unplatinated or platinated form were observed. The overall reduction of fragmentation on the $5^{\prime}$-side of the GG base pair was found to be less pronounced for platinated RNA than for platinated DNA.

As mentioned previously, a distinct fragmentation on the $3^{\prime}$-side of GG resulting in $\left.\mathrm{y}^{-}, \mathrm{w}^{-}, \mathrm{c}^{\mathrm{C}}+\mathrm{Pt}\right]^{-}$, and $\left[\mathrm{a}_{n-\mathrm{x}}+\mathrm{Pt}\right]$-ions, was observed. For CGGCUU and CCGGUU the abundance of the $\mathrm{w}_{1^{-}}(\mathrm{m} / \mathrm{z} 323.04), \mathrm{w}_{2^{-}}$ $\left(\mathrm{m} / \mathrm{z}\right.$ 314.04, 629.04), and $\mathrm{w}_{3}$-ion $(\mathrm{m} / \mathrm{z} 466.55)$ increased after addition of cisplatin. At first sight the $\mathrm{w}_{1}$-ion abundance in the product ion spectrum of CCGGUU + $\mathrm{Pt}$ even seems to exceed the signal of the $\mathrm{w}_{2}$-ion. After combining the intensities of the singly and doubly charged species $(\mathrm{m} / \mathrm{z} 314.04,629.04)$, it becomes clear that $w_{2}$-ion formation clearly outweighs the relative intensity of the $\mathrm{w}_{1}$-ion. The observation of increased $\mathrm{w}_{1}$-ion generation is in contrast to the behavior of DNA, which was found to point into the opposite direction. $\mathrm{w}_{1}$-Ions represent by far the most abundant fragment ions in the product ion spectra of unplatinated DNA (data not shown). After formation of the GG-DDP adducts in CGGCTT and CCGGTT, the relative intensity of the $\mathrm{w}_{1}$-ion decreased to about $20-30 \%$ of the abundance of the corresponding $\mathrm{w}_{\mathrm{x}}$-ion. In the case of CCTGGT $+\mathrm{Pt}$, this effect cannot be investigated since the $\mathrm{w}_{1}$-ion also constitutes the $\mathrm{w}_{\mathrm{x}}$-ion and hence, is the most intensive fragment anyway. This difference between RNA and DNA can most likely be attributed to the variation of the 2 '-substituent.

Another remarkable characteristic of the product ion spectra of platinated RNA is the increased occurrence of unplatinated a-B-ions, such as $\mathrm{a}_{3}-\mathrm{G}$ from CGGCUU + $\mathrm{Pt}$ and CCGGUU + Pt, $\mathrm{a}_{4}-\mathrm{G}$ from CCUGGU $+\mathrm{Pt}$, and $\mathrm{a}_{2}-\mathrm{G}$ from CGGCUU + Pt, in comparison to unplatinated oligoribonucleotides. They are generated by backbone cleavage in-between or 3'-adjacent to the GG base pair in combination with cleavage of the $\mathrm{N}$ glycosidic bond of one of the guanines. This indicates that platinated RNA is following the same fragmentation mechanism as proposed for their DNA analogues. In general, the increased formation of these a-B-ions further reveals the altered gas-phase dissociation of RNA due to the presence of cisplatin, since these fragments are highly atypical fragments with respect to previous studies.

Comparing the product ion spectra of platinated RNA and DNA, the complexity of the spectra is increased for RNA, while for DNA a rather simple picture with reduced fragment ion diversity is obtained. This is basically due to the additionally generated c-, $[\mathrm{c}+\mathrm{Pt}]-$, and $y$-ions in the spectra of platinated RNA, which do not occur in the spectra of the platinated DNA.

Experimental data revealed that the binding of cisplatin forces the dissociation of both types of oligonucleotides into a similar direction, despite the fact that in their unplatinated form they exhibit intrinsically different fragmentation pathways.

\section{Conclusion}

The investigation of the gas-phase behavior of platinated oligonucleotides has shown that their fragmentation is strongly altered in comparison to unmodified oligonucleotides. For oligodeoxynucleotides, two dissociation mechanisms are responsible for the generation of the all-dominating $\mathrm{w}_{\mathrm{x}}$-ion and the lack of a complementary-ion of equivalent abundance. The initial step of the dissociation cascade was found to originate from one specific phosphate group. Attack by the phosphate oxygen atom on the $3^{\prime}$-side of the cleavage site triggers the cleavage of the N-glycosidic bond. Subsequent 1,2-elimination from the ribose leads to backbone cleavage and the formation of characteristic [a $+\mathrm{Pt}]-$ and a-B-ions. Further degradation involves repeated 1,2elimination reactions, which preferentially arise from 
the phosphate groups on the $5^{\prime}$-side. However, studies on methylphosphonate-modified oligonucleotides demonstrated that phosphate groups at different positions within the backbone can be involved in the second and third dissociation step as well, thus, providing alternative routes to the final degradation products and decreasing the yield of a-ions. Experiments on oligoribonucleotides revealed that the typical dissociation pathway of RNA is altered due to platination. While unplatinated RNA preferentially generates $c$ and $y$ fragments, there is an increased formation of w-, a-B-, and [a + Pt]-ions from platinated RNA, due to backbone cleavage in proximity of the adduct site.

\section{Acknowledgments}

The authors gratefully acknowledge financial support of this work by the Swiss National Science Foundation (grant no. 200020111877).

\section{References}

1. Rosenberg, B.; Van Camp, L.; Krigas, T. Inhibition of Cell Division in Escherichia coli by Electrolysis Products from a Platinum Electrode. Nature 1965, 205(4972), 698-699.

2. Khan, A.; Hill, J. M. Immunosuppression with Cis-platinum (II) Diamminodichloride-Effect on Antibody Plaque-Forming Spleen Cells. Infect. Immun. 1971, 4(3), 320-321.

3. Jamieson, E. R.; Lippard, S. J. Structure, Recognition, and Processing of Cisplatin-DNA Adducts. Chem. Rev. 1999, 99(9), 2467-2498.

4. Reedijk, J. New Clues for Platinum Antitumor Chemistry: Kinetically Controlled Metal Binding to DNA. Proc. Natl. Acad. Sci. U.S.A. 2003, 100(7), 3611-3616.

5. Rosenberg, B. Noble Metal Complexes in Cancer Chemotherapy. Adv. Exp. Med. Biol. 1977, 91, 129-150.

6. Wong, E.; Giandomenico, C. M. Current Status of Platinum-Based Antitumor Drugs. Chem. Rev. 1999, 99(9), 2451-2466.

7. Adler, H. I.; Hardigree, A. A. Postirradiation Growth Division and Recovery in Bacteria. Radiat. Res. 1965, 25(1), 92-102.

8. Akaboshi, M.; Kawai, K.; Maki, H.; Akuta, K.; Ujeno, Y.; Miyahara, T. The Number of Platinum Atoms Binding to DNA, RNA and Protein Molecules of HELA-Cells treated with Cisplatin at Its Mean Lethal Concentration. Jpn J. Cancer Res. 1992, 83(5), 522-526.

9. Haraguchi, H. Metallomics as Integrated Biometal Science. J. Anal. At. Spectrom. 2004, 19(1), 5-14.

10. Harder, H. C. Inhibitory Effects of Anti-Tumor Platinum Compounds on DNA, RNA, and Protein Syntheses in Mammalian Cells In Vitro. Int. J. Cancer 1970, 6(2), 207-216.

11. Howle, J. A.; Gale, G. R. Cis-Dichlorodiammineplatinum (II): Persistent and Selective Inhibition of Deoxyribonucleic Acid Synthesis In Vivo. Biochem. Pharmacol. 1970, 19(10), 2757-2762.

12. Pascoe, J. M.; Roberts, J. J. Interactions Between Mammalian-Cell DNA and Inorganic Platinum Compounds. 1. DNA Interstrand Crosslinking and Cytotoxic Properties of Platinum(II) Compounds. Biochem. Pharmacol. 1974, 23(9), 1345-1357.

13. Reslova, S. The Induction of Lysogenic Strains of Escherichia coli by Cis-Dichlorodiammineplatinum (II). Chem. Biol. Interact. 1971, 4(1), 66-70.

14. Rosenkranz, H. S.; Garro, A. J.; Levy, J. A.; Carr, H. S. Studies with Hydroxyurea. I. The Reversible Inhibition of Bacterial DNA Synthesis and the Effect of Hydroxyurea on the Bactericidal Action of Streptomycin. Biochim. Biophys. Acta 1966, 114(3), 501-515.

15. Speelmans, G.; Sips, W.; Grisel, R. J. H.; Staffhorst, R.; FichtingerSchepman, A. M. J.; Reedijk, J.; de Kruijff, B. The Interaction of the Anti-Cancer Drug Cisplatin with Phospholipids is Specific for Negatively Charged Phospholipids and Takes Place at Low Chloride Ion Concentration. Biochim. Biophys. Acta Biomembranes 1996, 1283(1), 60-66.

16. Speelmans, G.; Staffhorst, R.; Versluis, K.; Reedijk, J.; de Kruijff, B. Cisplatin Complexes with Phosphatidylserine in membranes. Biochemistry 1997, 36(34), 10545-10550.

17. Witkin, E. M. The Radiation Sensitivity of Escherichia coli B: a Hypothesis relating Filament Formation and Prophage Induction. Proc. Natl. Acad. Sci. U.S.A. 1967, 57(5), 1275-1279.

18. Jansen, B. A. J.; Brouwer, J.; Reedijk, J. Glutathione Induces Cellular Resistance Against Cationic Dinuclear Platinum Anticancer Drugs. J. Inorg. Biochem. 2002, 89(3/4), 197-202.

19. Ghezzi, A.; Aceto, M.; Cassino, C.; Gabano, E.; Osella, D. Uptake of Antitumor Platinum(II)-Complexes by Cancer Cells, Assayed by Induc- tively Coupled Plasma Mass Spectrometry (ICP-MS). J. Inorg. Biochem. 2004, 98(1), 73-78.

20. Wang, D.; Lippard, S. J. Cellular Processing of Platinum Anticancer Drugs. Nat. Rev. Drug Discov. 2005, 4(4), 307-320.

21. Fichtinger-Schepman, A. M. J.; Vanderveer, J. L.; Denhartog, J. H. J.; Lohman, P. H. M.; Reedijk, J. Adducts of the Antitumor Drug CisDiamminedichloroplatinum(II) with DNA-Formation, Identification, and Quantitation. Biochemistry 1985, 24(3), 707-713.

22. Bosl, G. J.; Motzer, R. J. Testicular Germ-Cell Cancer. New Engl. J. Med. 1997, 337(4), 242-254.

23. McGowan, G.; Parsons, S.; Sadler, P. J. Contrasting Chemistry of Cisand Trans-Platinum(II) Diamine Anticancer Compounds: Hydrolysis Studies of Picoline Complexes. Inorg. Chem. 2005, 44(21), 7459-7467.

24. Eastman, A. Reevaluation of Interaction of Cis-Dichloro(Ethylenediamine) Platinum(II) with DNA. Biochemistry 1986, 25(13), 3912-3915.

25. Fichtinger-Schepman, A. M. I.; Vanoosterom, A. T. Lohman, P. H. M. Berends, F. Cis-Diamminedichloroplatinum(II)-Induced DNA Adducts in peripheral Leukocytes from 7 Cancer Patients-Quantitative Immunochemical Detection of the Adduct Induction and Removal after a Single Dose of Cis-Diamminedichloroplatinum(II). Cancer Res. 1987, 47(11), 3000-3004.

26. Poirier, M. C.; Reed, E.; Zwelling, L. A.; Ozols, R. F.; Litterst, C. L.; Yuspa, S. H. Polyclonal Antibodies to Quantitate Cis-Diamminedichloroplatinum(II)-DNA Adducts in Cancer Patients and Anima-Models. Environ. Health Perspect. 1985, 62(10), 89-94.

27. Reed, E.; Ozols, R. F.; Tarone, R.; Yuspa, S. H.; Poirier, M. C. PlatinumDNA Adducts in Leukocyte DNA Correlate with Disease Response in Ovarian-Cancer Patients Receiving Platinum-Based Chemotherapy. Proc. Natl. Acad. Sci. U.S.A. 1987, 84(14), 5024-5028.

28. Reed, E.; Yuspa, S. H.; Zwelling, L. A.; Ozols, R. F.; Poirier, M. C. Quantitation of Cis-Diamminedichloroplatinum-II (Cisplatin)-DNAIntrastrand Adducts in Testicular and Ovarian-Cancer Patients Receiving Cisplatin Chemotherapy. J. Clin. Investig. 1986, 77(2), 545-550.

29. Admiraal, G.; Vanderveer, J. L.; Degraaff, R. A. G.; Denhartog, J. H. J.; Reedijk, J. Intrastrand Bis(Guanine) Chelation of D(CpGpG) to Cisplatinum - an X-Ray Single-Crystal Structure Analysis. J. Am. Chem. Soc. 1987, 109(2), 592-594.

30. Yang, D. Z.; Vanboom, S.; Reedijk, J.; Vanboom, J. H.; Wang, A. H. J. Structure and Isomerization of an Intrastrand Cisplatin-Cross-Linked Octamer DNA Duplex by NMR Analysis. Biochemistry 1995, 34(39), 12912-12920.

31. Harder, H. C.; Smith, R. G.; Leroy, A. F. Template Primer Inactivation by Cis-Dichlorodiamine and Trans-Dichlorodiamine Platinum for Human DNA-Polymerase $\alpha, \beta$, and Rauscher Murine Leukemia-Virus Reverse-Transcriptase, as a Mechanism of Cytotoxicity. Cancer Res. 1976, 36(10), 3821-3829.

32. Hoffmann, J. S.; Johnson, N. P.; Villani, G. Conversion of Monofunctional DNA Adducts of Cis-Diamminedichloroplatinum(II) to Bifunctional Lesions-Effect on the In Vitro Replication of Single-StrandedDNA by Escherichia coli DNA-Polymerase-I and Eukaryotic DNA Polymerases- $\alpha$. J. Biol. Chem. 1989, 264(25), 15130-15135.

33. Johnson, N. P.; Hoeschele, J. D.; Kuemmerle, N. B.; Masker, W. E.; Rahn, R. O. Effects of Platinum Anti-Tumor Agents and Pyrimidine Dimers on In Vitro Replication of T7-DNA. Chem. Biol. Interact. 1978, 23(2), 267-271.

34. Pinto, A. L.; Lippard, S. J. Sequence-Dependent Termination of In Vitro DNA-Synthesis by Cis-Diamminedichloroplatinum(II) and TransDiamminedichloroplatinum(II). Proc. Natl. Acad. Sci. U.S.A. 1985, 82(14), 4616-4619.

35. Villani, G.; Hubscher, U.; Butour, J. L. Sites of Termination of In Vitro DNA-Synthesis on Cis-Diamminedichloroplatinum(Ii) Treated SingleStranded-DNA - a Comparison Between Escherichia coli DNA-Polymerase-I and Eukaryotic DNA Polymerases- $\alpha$. Nucleic Acids Res. 1988, 16(10), 4407-4418.

36. Corda, Y.; Job, C.; Anin, M. F.; Leng, M.; Job, D. Transcription by Eukaryotic and Prokaryotic RNA-Polymerases of DNA Modified at a D(GG) or a D(AG) Site by the Antitumor Drug Cis-Diamminedichloroplatinum(II). Biochemistry 1991, 30(1), 222-230.

37. Cullinane, C.; Mazur, S. J.; Essigmann, J. M.; Phillips, D. R.; Bohr, V. A Inhibition of RNA Polymerase II Transcription in Human Cell Extracts by Cisplatin DNA Damage. Biochemistry 1999, 38(19), 6204-6212.

38. Lemaire, M. A.; Schwartz, A.; Rahmouni, A. R.; Leng, M. Interstrand Cross-Links are Preferentially Formed at the D(GC) Sites in the Reaction Between Cis-Diamminedichloroplatinum(Ii) and DNA. Proc. Natl. Acad. Sci. U.S.A. 1991, 88(5), 1982-1985.

39. Sorenson, C. M.; Eastman, A. Mechanism of Cis-Diamminedichloroplatinum (II)-induced Cytotoxicity-Role of G2 Arrest and DNA Double-Strand Breaks. Cancer Res. 1988, 48(16), 4484-4488.

40. Gonnet, F.; Kocher, F.; Blais, J. C.; Bolbach, G.; Tabet, J. C.; Chottard, J. C. Kinetic Analysis of the Reaction Between d(TTGGCCAA) and $[\mathrm{Pt}(\mathrm{NH} 3)(3)(\mathrm{H} 2 \mathrm{O})](2+)$ by Enzymatic Degradation of the Products and ESI and MALDI Mass Spectrometries. J. Mass Spectrom. 1996, 31(7), 802-809.

41. Marchan, V.; Moreno, V.; Pedroso, E.; Grandas, A. Towards a Better Understanding of the Cisplatin Mode of Action. Chem. A Eur. J. 2001, 7(4), 808-815.

42. Meczes, E. L.; Azim-Araghi, A.; Ottley, C. J.; Pearson, D. G.; Tilby, M. J. Specific Adducts Recognized by a Monoclonal Antibody Against Cisplatin-Modified DNA. Biochem. Pharmacol. 2005, 70(12), 1717-1725.

43. Troujman, H.; Chottard, J. C. Comparison between HPLC and Capillary Electrophoresis for the Separation and Identification of the Platination 
Products of Oligonucleotides with Cis-[Pt(NH3)(2)(H2O)(2)](2+). Anal. Biochem. 1997, 252(1), 177-185.

44. Grotjahn, L.; Frank, R.; Blocker, H. Ultrafast Sequencing of Oligodeoxyribonucleotides by FAB-Mass Spectrometry. Nucleic Acids Res. 1982, 10(15), 4671-4678

45. Sindona, G.; Uccella, N.; Weclawek, K. Structure Determination of Isomeric Oligodeoxynucleotide Salts by Fast-Atom-Bombardment Mass-Spectrometry. J. Chem. Res. S 1982, 184-185.

46. Panico, M.; Sindona, G.; Uccella, N. Bioorganic Applications of Mass Spectrometry. 3. Fast-Atom-Bombardment-Induced Zwitterionic Oligonucleotide Quasimolecular Ions Sequenced by MS/MS. J. Am. Chem. Soc. 1983, 105(17), 5607-5610.

47. Cerny, R. L.; Gross, M. L.; Grotjahn, L. Fast-Atom-Bombardment Combined with Tandem Mass-Spectrometry for the Study of Dinucleotides. Anal. Biochem. 1986, 156(2), 424-435.

48. Wang, Z.; Wan, K. X.; Ramanathan, R.; Taylor, J. S.; Gross, M. L. Structure and Fragmentation Mechanisms of Isomeric T-Rich Oligodeoxynucleotides: A Comparison of Four Tandem Mass Spectrometric Methods. J. Am. Soc. Mass Spectrom. 1998, 9(7), 683-691.

49. Wan, K. X.; Gross, J.; Hillenkamp, F.; Gross, M. L. Fragmentation Mechanisms of Oligodeoxynucleotides Studied by H/D Exchange and Electrospray Ionization Tandem Mass Spectrometry. J. Am. Soc. Mass Spectrom. 2001, 12(2), 193-205.

50. Wan, K. X.; Gross, M. L. Fragmentation Mechanisms of Oligodeoxynucleotides: Effects of Replacing Phosphates with Methylphosphonates and Thymines with Other Bases in T-Rich Sequences. I. Am. Soc. Mass Spectrom. 2001, 12(5), 580-589.

51. Cerny, R. L.; Tomer, K. B.; Gross, M. L.; Grotjahn, L. Fast-AtomBombardment Combined with Tandem Mass-Spectrometry for Determining Structures of Small Oligonucleotides. Anal. Biochem. 1987, 165(1), 175-182.

52. Schürch, S.; Bernal-Mendez, E.; Leumann, C. J. Electrospray Tandem Mass Spectrometry of Mixed-Sequence RNA/DNA Oligonucleotides. J. Am. Soc. Mass Spectrom. 2002, 13(8), 936-945.

53. Tromp, J. M.; Schürch, S. Gas-Phase Dissociation of Oligoribonucleotides and Their Analogs Studied by Electrospray Ionization Tandem Mass Spectrometry. J. Am. Soc. Mass Spectrom. 2005, 16(8), 1262-1268.

54. Andersen, T. E.; Kirpekar, F.; Haselmann, K. F. RNA Fragmentation in MALDI Mass Spectrometry Studied by H/D-Exchange: Mechanisms of General Applicability to Nucleic Acids. J. Am. Soc. Mass Spectrom. 2006, 17(10), 1353-1368.

55. Puzo, G. Prome, J. C. Macquet, J. P. Lewis, I. A. S. Fast Atom Bombardment Mass-Spectra of the Bis-Guanosine Adduct with Cisplatin. Biomed. Mass Spectrom. 1982, 9(12), 552-556.

56. Roos, I. A. G.; Thomson, A. J.; Eagles, J. Mass-Spectrometric Studies of Interaction of Platinum Complexes with Nucleoside Analogs. Chem. Biol. Interact. 1974, 8(6), 421-427.

57. Hunt, D. F.; Hignite, C. E.; Biemann, K. Structure Elucidation of Dinucleotides by Mass Spectrometry. Biochem. Biophys. Res. Commun. 1968, 33(3), 378-383.
58. McCloskey, J. A.; Lawson, A. M.; Tsuboyama, K.; Krueger, P. M.; Stillwell, R. N. Mass Spectrometry of Nucleic Acid Components. Trimethylsilyl Derivatives of Nucleotides, Nucleosides, and Bases. J. Am. Chem. Soc. 1968, 90(15), 4182-4184.

59. Macquet, J. P.; Jankowski, K.; Butour, J. L. Mass-Spectrometry Study of DNA-Cisplatin Complexes-Pertubation of Guanine-Cytosine Base Pairs. Biochem. Biophys. Res. Commun. 1980, 92(1), 68-74.

60. Claereboudt, J.; Despiegeleer, B.; Debruijn, E. A.; Gijbels, R.; Claeys, M. Structural Characterizations of Cisplatin Analogs by Fast Atom Bombardment (FAB) and Laser Microprobe Mass-Spectrometry (LAMMA). J. Pharm. Biomed. Anal. 1989, 7(12), 1599-1610.

61. Martin, L. B. Schreiner, A. F. Vanbreemen, R. B. Characterization of Cisplatin Adducts of Oligonucleotides by Fast-Atom-Bombardment Mass-Spectrometry. Anal. Biochem. 1991, 193(1), 6-15

62. Costello, C. E.; Comess, K. M.; Plaziak, A. S.; Bancroft, D. P.; Lippard, S. J. Fast-Atom-Bombardment and High-Performance Tandem MassSpectrometry Of Platinum(II) Oligodeoxyribonucleotide Fragments. Int. J. Mass Spectrom. Ion Processes 1992, 122, 255-279.

63. Baik, M. H.; Friesner, R. A.; Lippard, S. J. Theoretical Study on the Stability of N-Glycosyl Bonds: Why Does N7-Platination not Promote Depurination? J. Am. Chem. Soc. 2002, 124(16), 4495-4503.

64. Iannitti-Tito, P.; Weimann, A.; Wickham, G.; Sheil, M. M. Structural Analysis of Drug-DNA Adducts by Tandem Mass Spectrometry. Analyst 2000, 125(4), 627-633.

65. Zhang, Q. R.; Yu, E. T.; Kellersberger, K. A.; Crosland, E.; Fabris, D. Toward Building a Database of Bifunctional Probes for the MS3D Investigation of Nucleic Acids Structures. J. Am. Soc. Mass Spectrom. 2006, 17(11), 1570-1581.

66. Iannitti, P.; Sheil, M. M.; Wickham, G. High Sensitivity and Fragmentation Specificity in the Analysis of Drug-DNA Adducts by Electrospray Tandem Mass Spectrometry. J. Am. Chem. Soc. 1997, 119(6), 1490-1491.

67. Barry, J. P.; Vouros, P.; Vanschepdael, A.; Law, S. J. Mass and Sequence Verification of Modified Oligonucleotides Using Electrospray Tandem Mass Spectrometry. J. Mass Spectrom. 1995, 30(7), 993-1006.

68. Marzilli, L. A.; Barry, J. P.; Sells, T.; Law, S. J.; Vouros, P.; Harsch, A. Oligonucleotide Sequencing Using Guanine-Specific Methylation and Electrospray Ionization Ion Trap Mass Spectrometry. J. Mass Spectrom. 1999, 34(4), 276-280.

69. Kirpekar, F.; Nordhoff, E.; Kristiansen, K.; Roepstorff, P.; Hahner, S.; Hillenkamp, F. 7-Deaza Purine Bases Offer a Higher Ion Stability in the Analysis of DNA by Matrix-Assisted Laser Desorption/lionization Mass Spectrometry. Rapid Commun. Mass Spectrom. 1995, 9(6), 525-531.

70. Carsey, T. P.; Boudreaux, E. A. The Electronic Structure of PlatinumGuanine Complexes. Chem. Biol. Interact. 1980, 30(2), 189-201.

71. Monn, S. T. M.; Schürch, S. New Aspects of the Fragmentation Mechanisms of Unmodified and Methylphosphonate-Modified Oligonucleotides. J. Am. Soc. Mass Spectrom. 2007, 18(6), 984-990. 